\title{
Seroprevalence of viral hepatitis in jaundiced pregnant women in a teritiary care hospital
}

\author{
Rudrapathy Parthiban", Raveendran Vinod, Saraswathi, Javangula Umarani \\ From 2nd International Science Symposium on HIV and Infectious Diseases (HIV SCIENCE 2014) \\ Chennai, India. 30 January - 1 February 2014
}

\section{Background}

Viral hepatitis represents an important health problem in the developing countries. The objective of this study is to determine the seroprevalence of viral hepatitis pattern in jaundiced pregnant women.

\section{Methods}

A total of 128 jaundiced pregnant women admitted as in-patients were included in the study. The test samples were screened for viral hepatitis markers; HBsAg, AntiHAV (IgM), Anti-HCV, Anti-HDV, Anti-HEV (IgM) by commercial ELISA kits. For HBsAg positive women, Anti-HBc IgM, HBeAg and Anti-HBe were done. HBV DNA analysis was done by polymerase chain reaction.

\section{Results}

Of the 128 test serum samples screened, 53.1\% were positive for HBsAg, 15.62\% were positive for HEV IgM and $3.25 \%$ were positive for HAV IgM. None of them were positive for Anti-HCV \& Anti-HDV. Among the $68 \mathrm{HBsAg}$ positive pregnant women, the prevalence of $\mathrm{HBeAg}$, anti-HBe, and anti-HBc were $54 \%, 45.6 \%$ and $89 \%$, respectively. Of the $31, \mathrm{HBeAg}$ negative women, 11 had only anti-HBe, 9 were positive for anti-HBe and HBV DNA and 11 were negative for anti-HBe and HBV DNA.

\section{Conclusion}

The present study conducted has evolved a comprehensive picture on the virological pattern of viral hepatitis in jaundiced pregnant women. Hepatitis B virus (53.1\%) seems to be the major causative agent followed by Hepatitis E virus (15.62\%) in the 128 study subjects. Authenticated documentation on pregnancy hepatitis,

* Correspondence: parthi71975@gmail.com

Sri Venkateshwaraa Medical College Hospital \& Research centre, Puducherry, India 